\title{
AURÉLIA CAMARGO: SUJEITO FEMININO DE DIREITO E DE LINGUAGEM - O DISCURSO JURÍDICO EM SENHORA, DE JOSÉ DE ALENCAR
}

\author{
Luana Paixão Dantas do Rosário ${ }^{1}$ \\ Jỗo Mateus Silva Fagundes Oliveira ${ }^{2}$
}

\begin{abstract}
RESUMO: O presente artigo tem por objetivo problematizar o que o discurso jurídico ficcional na narrativa literária de Senhora desvela sobre o aparente empoderamento de Aurélia Camargo, que se constitui, em tensa relação de assujeitamento, como protagonista do romance, em sujeito feminino de direito e de linguagem. Para tanto, será necessário identificar elementos de discurso jurídico existentes no romance por meio dos institutos jurídicos e os papéis de gênero vigentes à época em que viveu José de Alencar. Utilizará a hermenêutica e a análise do discurso, numa matriz epistemológica fenomenológica. Terá como marco teórico a relação que Foucault estabelece entre discurso e poder e a premissa de que os fenômenos jurídico e literário se constituem como discursos ficcionais, a partir das Teorias Imaginária e Po(i)ética do Direito e do Movimento Direito e Literatura, sob os postulados teóricos de Guerra Filho, Cantarini e Trindade, além de contribuições de M. Bakhtin. Conclui pelo reconhecimento de um discurso jurídico no romance Senhora, de viés patrimonialista e patriarcalista, que desvela expectativas de comportamento da sociedade oitocentista. Além disso, demonstra a protagonista enquanto sujeito feminino de direito e de linguagem, cuja constituição nessas categorias ocorre sob uma perspectiva masculina e de empoderamento frustrado.
\end{abstract}

Palavras-chave: direito e literatura; teoria imaginária do direito; teoria poética do direito; José de Alencar.

1 Doutora e Mestre em Direito Público pela Universidade Federal da Bahia (UFBA). Professora Adjuntaente no Departamento de Ciências Jurídicas da Universidade Estadual de Santa Cruz (UESC). Líder do Grupo de Pesquisa em Jurisdição Constitucional, Hermenêutica e Democracia (JCHD).Editora da Revista Científica Diké. Ilhéus, BA. CV Lattes: http://lattes.cnpq.br/6220730804457925. E-mail: lpdrosario@uesc.br.

2 Pós-graduando em Direito Processual Civil pela Universidade Estácio de Sá (UNESA). Bacharel em Direito pela Universidade Estadual de Santa Cruz (UESC). Membro do Grupo de Pesquisa em Jurisdição Constitucional, Hermenêutica e Democracia (JCHD). Ilhéus, BA. CV Lattes: http://lattes.cnpq.br/9857854488220633. E-mail: joaomateusfagundes@gmail.com. 


\section{INTRODUÇÃO}

A partir de marco teórico sobre a relação intrínseca entre direito e literatura e sobre a natureza ficcional do direito, abre-se a possibilidade de análise dos discursos jurídicos ficcionais presentes na literatura para se compreender não somente o direito, mas a própria sociedade. Para alcançar os fins a que se propõe, este trabalho realizará a aproximação entre a escola teórica do direito na literatura e a tradição francesa da análise do discurso. Julgamos ser possível fazer a análise dos discursos jurídicos que se presentificam no universo literário, até porque, como se verá adiante, o discurso jurídico, no âmbito literário ou não, é ficcional. Consideraremos que o narrador, sujeito enunciador de Senhora, vocaliza o literato e o seu tempo, nos termos de Michel Foucault (1971), ser histórico, constructo da linguagem, sujeitado e objetivado.

A partir da premissa foucaultiana de que o discurso é troca, disputa pelo poder e de poder, questionaremos, neste trabalho, o que o discurso jurídico presente no universo ficcional de Senhora nos desvela acerca da protagonista enquanto sujeito feminino de direito e de linguagem, representativo dos papéis de gênero vigentes à época em que viveu José de Alencar. Empregaremos a noção foucaultiana de sujeito, entendido como ser de linguagem que se constitui em relações de assujeitamento.

Destarte, o objetivo deste trabalho é averiguar o que o discurso jurídico presente na narrativa literária de Senhora revela sobre o aparente empoderamento de Aurélia Camargo, que se constitui, em tensa relação de assujeitamento, em sujeito feminino de direito e de linguagem.

A hipótese de pesquisa a ser 'verificada' é de que o romance Senhora aponta um discurso jurídico de ordem patriarcalista e patrimonialista e, nesse viés, constrói a narrativa de aparente empoderamento feminino pela aquisição do patrimônio e consequente constituição como sujeito feminino de direito no bojo de intrincadas relações de assujeitamento. Para essa 'verificação', o presente artigo utiliza como metodologias a hermenêutica fenomenológica e a análise do discurso de matriz francesa, com base nas autoras Helena Brandão e Eni Orlandi, e a coexistência de métodos se dá a partir do pluralismo fenomenológico.

Em face da relevância da obra de José de Alencar, segundo Antonio Candido (2006) veiculada através dos folhetins e que atingiria expressivo 
número de leitores, justifica-se o desenvolvimento desta pesquisa pela possibilidade de o autor ter influenciado, direta ou indiretamente, em relação dialética, posicionamentos coletivos sobre, por exemplo, o instituto do casamento, tema transversalmente apresentado em Senhora. Aliado a isso, a escassez de trabalhos que tratem da relação entre direito e literatura, diante da manutenção da tradição kantiana na matriz epistemológica do direito $^{3}$ e da perpetuação da dogmática acrítica, reforça a pertinência desse enfoque temático, de forma a produzir, nas limitações próprias de um artigo científico, novos olhares para o direito, para além dos tradicionais estudos com enfoque legislativo, doutrinário e jurisprudencial, que não conseguem dar conta da complexidade do fenômeno jurídico.

Este trabalho iniciará fixando o direito como discurso ficcional. Contextualizará o Movimento Direito e Literatura, a partir de André Karam Trindade, caracterizará a vertente teórica Direito na Literatura e apresentará o marco teórico da Teoria Imaginária e po(i)ética do Direito, de Willis Santiago Guerra Filho e Paola Cantarini. A partir daí explicará a necessidade da utilização dos postulados da análise do discurso formulados por Helena Brandão, para extrair, da interpenetração entre o direito e a literatura, do ponto de articulação dos processos ideológicos e dos fenômenos linguísticos, o desvelamento do discurso jurídico de ordem patriarcalista e patrimonialista.

Após, será feita a análise do discurso de institutos jurídicos explorados no romance, como a distinção entre filhos legítimos e ilegítimos, a herança e a tutela. Também serão examinados costumes de época narrados no romance, como a 'amostra de balcão'. A legislação da época (as Ordenações Filipinas), no que interessa à narrativa, será abordada. Serão cruciais a teoria imaginária do direito e a teoria do empoderamento feminino de Srilatha Batliwala.

Especial atenção é dada à análise de trechos da obra, inclusive diálogos da personagem Aurélia que versam sobre o casamento. Aqui, se somarão à análise do discurso de origem francesa, os recursos da teoria da

3 O sujeito do direito vincula-se à compreensão de indivíduo apto a raciocinar e agir livremente tornando-se submetido a uma ordem jurídica, tal qual o homem racional kantiano, por possuir uma estrutura universal, necessária e a priori que organiza necessariamente a realidade em termos das formas da sensibilidade e dos conceitos e categorias do entendimento (Kant, 2003). 
polifonia, de Bakhtin, e os afluxos teóricos de Michel Foucault sobre assujeitamento. Por fim, na análise de Aurélia Camargo, protagonista de Senhora, enquanto sujeito/assujeitado feminino de direito e de linguagem, são trazidas reflexões de gênero de Simone de Beauvoir e Pierre Bourdieu, a fim de se verificar a hipótese de trabalho e de se alcançar o objetivo pretendido.

\section{DIREITO E LITERATURA: DISCURSOS FICCIONAIS}

Acerca da proximidade entre direito e literatura, tomaremos de empréstimo ensinamento de Lenio Streck (2013), segundo o qual, direito e literatura, ao desvelarem a presença da realidade nas ficções, desvelam também quanta ficção conforma nossa realidade. Do que extraímos que, da narrativa literária, podemos inferir padrões sociais, de gênero, bem como informações acerca do sistema jurídico. Assim como é possível concluir, com algum auxílio, como se exporá adiante, que o próprio discurso jurídico, é ficcional. Acerca da proximidade entre direito e literatura, mais remotamente, encontramos a máxima oitocentista presente na obra Von der Poesie im Recht (Da poesia no direito), de Jacob Grimm (1882, online): "Não é difícil acreditar que o direito e a poesia tenham se levantado da mesma cama" (tradução nossa)4.

Como bem nos asseveram Guerra Filho e Cantarini (2015), a partir do entendimento do direito como criação humana, tem sido proposta uma compreensão do universo jurídico em aproximação com o ficcional e, mais especificamente, com a literatura. Nesse viés, encontram-se, conforme nos aponta Guerra Filho (2010), estudos desenvolvidos pelos teóricos que compõem o Law \& Literature Movement (Movimento Direito e Literatura). Trindade (2012) apresenta a diversidade de abordagens ${ }^{5}$ do Movimento Direito e Literatura. Três vertentes são apresentadas: Law in Literature,

4 No original, "Dasz recht und poesie miteinander aus einem bette aufgestanden waren, hält nicht schwer zu glauben".

5 A segunda vertente, "Direito como Literatura" (Law as Literature), desenvolvida, segundo o autor, sobretudo nos Estados Unidos, caracteriza-se pela aplicação dos métodos de análise e interpretação próprios da crítica literária para o exame de textos e discursos jurídicos, com o objetivo de analisar a racionalidade das construções realizadas no âmbito das decisões judiciais. Por fim, tem-se o "Direito da Literatura" (Law of Literature), nem sempre considerada como parte do Movimento, mas sim como uma aproximação transversal que se ocupado estudo da propriedade intelectual, dos direitos autorais, de crimes contra a imprensa, liberdade de expressão, censura e regulações do exercício da atividade profissional literária. 
Law as Literature, Law of Literature. Este trabalho se insere na abordagem Law in Literature, desenvolvida, segundo o autor, sobretudo, na Europa, e que se liga à dimensão ética da narrativa e examina aspectos da problemática e da experiência jurídica retratados pela literatura. Esta é entendida como obra literária e "como documento de aplicação do direito e da consciência jurídica, a partir da ideia de que a virtualidade representada pela narrativa possibilite alcançar uma melhor compreensão do direito e seus fenômenos" (Trindade, 2012, p. 149-150).

$\mathrm{Na}$ linha de produções que aproximam o estudo entre direito e literatura, encontra-se a Teoria Imaginária e po(i)ética ${ }^{6}$ do Direito, de Guerra Filho e Cantarini (2015), que serve de pano de fundo a este trabalho. As Teoria Imaginária e Po(i)ética do Direito, em contraposição à tradição racionalista, passam a entender o direito em sua forma originária e fundamental, qual seja, a das imagens, do imaginário. Os autores destacam que o direito possui um caráter imaginário, sendo o modo pelo qual a sociedade conhece o comportamento esperado de cada um de seus membros. Assim, o direito não trata de uma simulação do que é real, mas, cria outra realidade, de natureza deontológica, com um modo de construção próprio. Conforme os autores, tal qual a ficção, como um sonho coletivo, o direito é construído pelo ser humano, de maneira difusa, e dotado de caráter vinculante. Com isso, dá-se ao direito a concepção de possível, de imaginário. Não por acaso, Jacob Grimm (1882, online) salientou: "Os dois [direito e poesia] se originam de dois essenciais, o fantástico e aquilo em que acreditamos" (tradução nossa)7.

O mundo ficcional, ensinam-nos Guerra Filho e Cantarini (2015, p. 32), "é um mundo de possibilidades reduzidas, onde não se pode saber sobre o que não nos é dado a conhecer pelos responsáveis por sua criação”. Os juízos formulados no âmbito do universo ficcional, portanto, são diferentes da realidade propriamente dita, uma vez que naquele universo só se pode saber o que nos informam os autores das obras, seja na literatura, seja no direito. Com isso, persiste a pergunta quanto às razões dessa

6 As Teoria Imaginária e po(i)ética do Direito destacam o caráter autopoiético do Direito e a necessária e indissolúvel vinculação dele com a filosofia, com o teatro e a literatura.

7 No original, "Ihr beider ursprung beruhet auf zweierlei wesentlichem, auf wunderbaren und dem glaubreichen“. 
ocultação. Acreditamos que as razões da ocultação residem na ideologia. Neste trabalho não há espaço para tratar de tema complexo como a ideologia, mas tomamos de empréstimo o recorte feito por Bernard Edelman ${ }^{8}$ (1976). Segundo o autor, o direito ocupa esse lugar único donde pode sancionar pelo constrangimento a sua ideologia, que está oculta. Conforme Edelman, a ideologia jurídica não faz mais do que especificar juridicamente a ideologia burguesa. A partir desse recorte, inferimos que a literatura romântica de Senhora nos mostra uma visão ideológica da urbe burguesa do país independente. Se em Edelman (1976) a ciência burguesa do direito viveu, talvez a literatura nos dê a chave para compreensão desse direito.

Desse modo, a interpenetração entre o direito e a literatura acaba por clamar, para nós, a utilização da análise do discurso, que, conforme Brandão (2004), compreende a linguagem, ao mesmo tempo, como formal e atravessada por entradas subjetivas e sociais. Essa instância se apresenta como ponto de articulação dos processos ideológicos e dos fenômenos linguísticos. A linguagem enquanto discurso, ainda na lição da mesma autora, não é neutra, nem inocente, nem natural: é o "sistema-suporte das representações ideológicas”. Agregando-se a essa noção a compreensão de Foucault (2015), para o qual o discurso é o espaço em que saber e poder se articulam, pois, aquele que fala, fala de algum lugar, a partir de um direito reconhecido institucionalmente, e esse discurso, que passa por verdadeiro, veicula o saber institucional e é gerador de poder, chegamos à conclusão de que o saber literário também veicula discursos, selecionados previamente por seus criadores. É o que buscaremos na análise do discurso jurídico presente em Senhora.

Conforme Guerra Filho e Cantarini (2015, p. 41), na interessante síntese sobre direito e ficção, "a ficção é a verdade do Direito, e o Direito é a camuflagem do poder". Se o Direito é o Poder que se camufla, que não se assume enquanto tal, ele encena uma narrativa, uma verdade ficcionalizada, no discurso que enuncia. Fixadas tais premissas, é possível averiguar de que forma as narrativas literária e jurídica se fazem presentes em Senhora, que passamos a analisar.

8 O filósofo e jurista francês trata de outra forma de representação narrativa em seu $O$ direito captado pela fotografia: elementos para uma teoria marxista do direito (Edelman, 1976). 


\section{A NARRATIVA DA HERANÇA}

A narrativa se conduz sob a perspectiva de Aurélia Camargo, protagonista do romance. A exigência de sua condição de sujeito, que será mais aclarada na seção própria, é impulsionada por um fenômeno jurídico: o direito sucessório. Com isso, temos que voltar a pesquisa aos conceitos jurídicos e costumes do Segundo Império. Diria Heidegger (2005, p. 45) “o tempo é o ponto de partida do qual a pre-sença sempre compreende e interpreta implicitamente o ser”. Temos, pois, que nossa análise de Senhora é situada temporalmente, uma síntese do que era quando a obra foi escrita, com aquilo que o intérprete da atualidade, permeado pela sua historicidade, apreende do ente. Dito isso, passemos à análise da obra alencariana.

Aurélia é filha de Emília Lemos e Pedro de Sousa Camargo. Pedro de Sousa Camargo é filho natural de Lourenço de Sousa Camargo. Tal categoria advém das Ordenações Filipinas, e se referia a uma espécie de filho ilegítimo, aquele nascido de pessoas solteiras ou viúvas (Almeida, 1870). Conforme a legislação, o filho natural de pai nobre não seria contemplado na sucessão aberta se aquele não tivesse deixado testamento, nem poderia concorrer com os filhos legítimos do falecido ou com qualquer de seus ascendentes, tendo direito apenas aos alimentos.

Pedro de Sousa Camargo, o filho natural que mais tarde tornar-se-ia o pai de Aurélia Camargo, estudava Medicina às expensas do pai, que, nas palavras do narrador (Alencar, 1999, p. 85) "não o tinha porém reconhecido, o que era de suma importância, pois além de existir a mãe do fazendeiro lá para as bandas de Minas [ascendente do autor da herança], o sujeito ainda estava robusto e podia bem casar-se e ter filhos legítimos”. Trechos como esse desvelam como o discurso jurídico permeia a narrativa literária alencariana. À luz da Teoria Imaginária do Direito é possível perceber que o direito possui um sentido ficcional, figurando como produto do desejo. A distinção entre filhos vigente à época e abolida pela Constituição de $1988^{9}$ nada mais é que uma ficção jurídica, com o fito específico de perpetuação da ideologia burguesa patriarcal e patrimonialista, na medida em que classificar filhos havidos fora do

9 Conforme o artigo 227, $\S 6^{\circ}$, da Constituição vigente, “os filhos, havidos ou não da relação do casamento, ou por adoção, terão os mesmos direitos e qualificações, proibidas quaisquer designações discriminatórias relativas à filiação". 
casamento como ilegítimos é típica forma de controle da sexualidade feminina e de presunção de paternidade dos filhos havidos no casamento para fins sucessórios.

$\mathrm{O}$ viés patrimonialista atinente à qualidade de filho ilegítimo é extraído da obra, dentre outros trechos, em “[...] Pedro Camargo era filho natural ainda não reconhecido; seu futuro dependia exclusivamente da vontade do pai, que podia abandoná-lo como a um estranho, deixando-o reduzido à indigência [...]" (Alencar, 1999, p. 88). Notamos nesses excertos que a narrativa literária - cuja síntese é necessária para situarmos a protagonista que será objeto de análise - informa-nos institutos jurídicos vigentes à época.

Os trechos citados também nos permitem perceber que a questão patrimonial é central para o desenrolar da narrativa e a formação da personalidade da personagem. Filho natural (filho ilegítimo de pessoa solteira ou viúva), Pedro Camargo, ao morrer sem reconhecimento do pai, deixa a sua filha Aurélia crescer desamparada. Com a morte do pai e diante dos problemas de saúde da mãe, Aurélia expõe-se à janela na tentativa de arranjar um casamento, sendo submetida a galanteios vulgares, e recebe a proposta de seu tio para que se torne prostituta. Aqui se percebe o viés patriarcal em duas práticas jurídico-sociais vigentes à época, desveladas pelo enredo: a exposição da mulher à janela - denominada (Alencar, 1999, p. 93) "amostra de balcão" - e o casamento arranjado. Será o casamento fundamental para a conversão de Aurélia em Senhora, com todas as nuances de significados que esse signo traz na obra, desde o seu título e subtítulo: "Senhora: perfil de mulher".

A prática da exposição da mulher à janela tinha o sentido de que ela estava solteira e disponível para propostas de casamento, no intuito de chamar a atenção de homens que passassem pela rua. Segundo Cida Golin (2002), havia um sentido especial nas janelas particulares para as mulheres cariocas do século XIX, verdadeiros "camarotes dos acontecimentos públicos”, porquanto indicavam a distância do sujeito de determinados eventos tidos por coletivos e abrangentes pelo registro oficial da história.

O casamento arranjado correspondia, como nos explica Renato Drummond Tapioca Neto (2014), a uma espécie de contrato social entre as elites brancas, com o fito específico de elevar ou manter o status econômico 
entre as famílias, que em Senhora surge como uma forma lícita de ascensão política e econômica do noivo, através do dote concedido pela nubente.

No Livro V, Título XXII das Ordenações Filipinas (Almeida, 1870), percebemos que os arranjos matrimoniais eram tão fortemente controlados que, caso os interessados se casassem sem autorização dos pais, podiam ser deserdados, isto é, perdiam seus direitos sucessórios, penalidade que apenas não seria imposta se o pretendente fosse de melhor condição do que o escolhido pelos pais (denotando-se o forte patrimonialismo da legislação).

As menções à "amostra de balcão" e ao casamento arranjado dão-nos ideia acerca dos papéis de gênero vigentes no Brasil Imperial. A figura feminina é associada ao de objeto disponível no mercado matrimonial, figura capaz de gerar riqueza, relegando-se sua vontade (e mesmo o amor, ideal vastamente trabalhado no Romantismo, escola literária em que se insere Senhora) a segundo plano e mantendo-se as bases do pensamento patriarcalista. Tais institutos corroboram para que ratifiquemos a Teoria Imaginária do Direito, desvelando-se o fenômeno jurídico através da Literatura, na medida em que os comportamentos esperados dos membros da sociedade da época revelam-se como sonhos coletivos e semiconscientes - o matrimônio ideal, a mulher ideal, os projetos de vida dos membros das famílias da urbe burguesa da capital do Império.

Após falecimento de sua mãe, Aurélia foi surpreendida pelo correspondente do seu falecido avô paterno, Lourenço, com quem tinha se reconciliado. Na correspondência, Lourenço reconhece o pai de Aurélia como filho e torna Aurélia sua herdeira. O narrador (Alencar, 1999, p. 117) expõe um verdadeiro estratagema para que uma neta oriunda de filho natural se tornasse herdeira:

O papel continha o testamento em que Lourenço de Sousa Camargo reconhecia e legitimava como seu filho a Pedro Camargo, que fora casado com D. Emília Lemos; declarando que à sua neta $\mathrm{D}$. Aurélia Camargo, nascida de um legítimo matrimônio, instituía sua única $\mathrm{e}$ universal herdeira (grifo nosso).

Perceba-se o destaque ao fato de Aurélia ser nascida de um legítimo matrimônio como condição legal para se constituir como herdeira, do que se extrai o teor patriarcalista da narrativa. Desvelam-se aqui duas formações discursivas peculiares: Alencar ressalta a legitimidade do 
matrimônio como instituidor de definições jurídico-sociais de relevância e status, ao mesmo tempo em que torna a herança uma construtora do empoderamento, isto é, o patrimônio se torna uma possibilidade para a assunção feminina. Retomamos, aqui, a lição de Edelman (1976), para relacioná-la à obra em análise. O matrimônio e, portanto, o direito acaba por funcionar ideologicamente, especificando, juridicamente, a ideologia burguesa.

A noção de empoderamento a que nos referimos possui ligação com o processo de desafio das relações de poder existentes e de obtenção de maior controle sobre as fontes de poder, conforme os postulados teóricos de Batliwala (1997). Esse entendimento, que perpassa a afirmação individual, a resistência coletiva, o protesto e a mobilização para desafiar as relações de poder, compreende o reconhecimento das forças sistêmicas que oprimem e a atuação para mudá-las. Segundo Batliwala (1997), o empoderamento das mulheres desafia a ideologia patriarcal, de dominação masculina e subordinação da mulher, bem como almeja transformar estruturas e instituições que reforçam e perpetuam a discriminação de gênero e a desigualdade social e capacitar mulheres pobres para que possam ter acesso e controle dos recursos materiais e informacionais. Esse fenômeno, com Aurélia Camargo, não se deu em totalidade. Embora haja afirmação individual de desafio das relações de poder existentes, não se chega ao reconhecimento das forças sistêmicas de opressão feminina e dominação masculina. A posição de Aurélia é peculiar e individual, inexistindo, na obra, elementos que demonstrem a resistência coletiva, o protesto e a mobilização. Considerando os afluxos ideológicos preponderantes no fim do século XIX, é de se reconhecer que ocorreu um fenômeno de empoderamento, ainda que frustrado, com a protagonista de Senhora.

Com a aquisição da herança, os parentes de Aurélia Camargo aproximam-se imediatamente da protagonista, e, enquanto era bajulada, o seu tio Lemos arranjava do juiz de órfãos a nomeação de tutor da sobrinha. Aurélia aceita a ideia de ter um tutor que fosse por ela dominado. Nas palavras do narrador (Alencar, 1999, p. 117): “De primeiro impulso, Aurélia pensou em revoltar-se contra essa nomeação, mostrando ao juiz a infame carta que lhe escrevera o tio; mas além de repugnar-lhe o escândalo, sorriulhe a ideia de ter um tutor a quem dominasse". 
Sobre a aquisição do patrimônio, expõe o autor (1999, p. 117):

A riqueza, que lhe sobreveio inesperada, erguendo-a subitamente da indigência ao fastígio, operou em Aurélia rápida transformação; não foi, porém, no caráter, nem nos sentimentos que se deu a revolução; estes eram inalteráveis, tinham a fina têmpera de seu coração. A mudança consumou-se apenas na atitude, se assim nos podemos exprimir, dessa alma perante a sociedade.

Aurélia Camargo passava a ser figura importante "da sociedade", graças ao patrimônio adquirido com a herança. Mas era necessário sacramentalizar, numa instituição, seu papel diante da elite fluminense. Para isso, Alencar recorreu ao casamento.

\section{A NARRATIVA DO CASAMENTO}

O instituto do casamento, sobre o qual se debruça o presente trabalho neste momento, é tratado, ainda no primeiro capítulo da primeira parte de Senhora ("O preço"), através de quatro expressões. O narrador (Alencar, 1999, p. 17) menciona que Aurélia daria aos pretendentes "certo valor monetário", que "cotava os seus adoradores pelo preço que razoavelmente poderiam obter no mercado matrimonial", que aqueles que a cortejavam “divertiam-se com o jogo que muitas vezes resultava do ágio de suas ações naquela empresa nupcial "e, ainda, que, se o pretendente fizesse algo a contento da moça, satisfazendo suas fantasias, ela "elevava-lhe a cotação". O que todas essas expressões apresentam em comum é o caráter patrimonialista do instituto do matrimônio no sistema social e jurídico brasileiro da segunda metade do séc. XIX e, por consequência, na representação oferecida pela literatura alencariana.

No Título XLVI do Livro IV, intitulado de "Como o marido e mulher são meeiros em seus bens", as Ordenações Filipinas descrevem modalidades de casamento (Almeida, 1870, online): um, pelo qual “[...] o marido e mulher forem casados per palavras de presente à porta da Igreja, ou per licença de prelado fora della, havendo copula carnal, serão meeiros em seus bens e fazenda [...]" e, outro, que hoje mais se assemelha à união estável, pelo qual "outrosi serão meeiros, provando que stiveram em casa teúda e manteúda, ou em casa de seu pai, ou em outra, em pública voz e fama de marido e mulher per tanto tempo, que segundo Direito baste para se presumir Matrimônio antreelles [...]”. 
A normatividade, ao aventar acerca do casamento, deu tons notadamente patrimoniais. Observam Flávia David Vieira e Edvania Gomes da Silva (2015) a inexistência de capítulo exclusivo para regular o instituto e a ênfase da legislação à repercussão patrimonial do matrimônio, já que foi adotado, no Título XLVI, o regime de bens da Carta a metade, que equivaleria, resguardando-se as especificidades do tratamento atual, à comunhão universal de bens, limitando-se o diploma legislativo à regulamentação de bens e obrigações entre cônjuges, enviesado por noções da religiosidade católica. Tal sacramentalidade é representada na cerimônia matrimonial que figura na obra, quando o romancista jurista introduz elemento de direito sucessório. Numa dimensão simbólica, anuncia Aurélia, na obra de Alencar (1999, p. 76), “[...] Não é tão extravagante o que faço agora, pois o testamento também faz parte da confissão”. E prossegue: “[...] Quero aproveitar este momento em que ainda sou senhora de mim e das minhas vontades, para declarar a última, que foi também a primeira de minha vida”. O narrador justifica a razão de tal ato:

A associação de dois atos tão opostos, a aurora da existência e sua despedida; a ideia da morte a entrelaçarse naquela mocidade tão rica de todas as prendas; a grinalda de noiva cingindo uma fronte a desfalecer; esse contraste era para deixar funda impressão no ânimo.

O instituto do casamento, embora mais socialmente ritualizado que juridicamente regulamentado, possui sentido especial para a mulher na família burguesa brasileira a partir do século XIX, como nos explica Maria Ângela D'Incao (2001, p. 229):

[...] Mulheres casadas ganhavam uma nova função: contribuir para o projeto familiar de mobilidade social através de sua postura nos salões como anfitriãs e na vida cotidiana, em geral, como esposas modelares e boas mães. Cada vez mais reforçada a ideia de que ser mulher é ser quase integralmente mãe dedicada e atenciosa, um ideal que só pode ser plenamente atingido dentro da esfera da família "burguesa e higienizada". Os cuidados e a supervisão da mãe passam a ser muito valorizados nessa época, ganha força a ideia de que é muito importante que as próprias mães cuidem da primeira educação dos filhos e não os deixem simplesmente soltos sob a influência de amas, negras ou "estranhos", "moleques" da rua.

Em Senhora, no entanto, há uma inversão dessa lógica, ainda que não venha a se tornar definitiva. Aurélia Camargo, antes apaixonada e renegada 
por Fernando Seixas, que a trocara por Adelaide Amaral, por pretensões puramente econômicas, inicia a execução de seu projeto de vingança. Negocia seu próprio casamento e propõe a Seixas o dote de cem mil contos de réis, impondo a condição de que a identidade da noiva não lhe seria revelada até o matrimônio. Fernando Seixas, diante de tal quantia, aceita as condições de Aurélia, que reforça, nos diálogos travados com o cônjuge, a sua posição negocial mesmo após o enlace, como o caráter patrimonial do casamento, que figura como instrumento de seu empoderamento em curso, numa demonstração de que o Direito é a camuflagem do Poder.

Vejamos trechos do diálogo na noite de núpcias, que nos é oferecido pelo narrador (1999, p. 80):

- Então nunca amou a outra?

- Eu lhe juro, Aurélia. Estes lábios nunca tocaram a face de outra mulher, que não fosse minha mãe. $\mathrm{O}$ meu primeiro beijo de amor, guardei-o para minha esposa, para ti...

Soerguendo-se para alcançar-lhe a face, não viu Seixas a súbita mutação que se havia operado na fisionomia de sua noiva.

Aurélia estava lívida, e a sua beleza, radiante há pouco, se marmorizara.

- Ou para outra mais rica!... disse ela retraindo-se para fugir ao beijo do marido, e afastando-o com a ponta dos dedos.

A voz da moça tomara o timbre cristalino, eco da rispidez e aspereza do sentimento que lhe sublevava o seio, e que parecia ringir-lhe nos lábios como aço.

- Aurélia! Que significa isto?

- Representamos uma comédia, na qual ambos desempenhamos o nosso papel com perícia consumada. Podemos ter este orgulho, que os melhores atores não nos excederiam. Mas é tempo de pôr termo a esta cruel mistificação, com que nos estamos escarnecendo mutuamente, senhor. Entremos na realidade por mais triste que ela seja; e resigne-se cada um ao que é, eu, uma mulher traída; o senhor, um homem vendido.

- Vendido! Exclamou Seixas ferido dentro d'alma.

- Vendido sim: não tem outro nome. Sou rica, muito rica, sou milionária; precisava de um marido, traste indispensável às mulheres honestas. $\mathrm{O}$ senhor estava no mercado; comprei-o. Custou-me cem contos de réis, foi barato; não se fez valer. Eu daria o dobro, o triplo, toda a minha riqueza por este momento.

Esse diálogo demonstra, em diversos trechos, a noção patrimonialista que a obra de Alencar nos desvela e que, diante da polifonia do sujeito, noção de Mikhail Bakhtin que desenvolveremos no próximo tópico, mostrase como voz da sociedade do Brasil Imperial. O beijo de amor seria 
guardado para a mais rica, conforme argumenta Aurélia, que, ao qualificar os sujeitos da relação, impõe uma adjetivação de denotação comercial ao seu marido: um homem vendido. Ao mesmo tempo, ela o qualifica como traste indispensável - isto é, o casamento era uma necessidade impositiva à época. Era através do enlace matrimonial que a mulher poderia ser, de qualquer modo, considerada verdadeira integrante "da sociedade". O homem, pois, era indispensável à constituição do sujeito feminino, ainda que fosse um "traste”. Após, a ênfase na mercantilização da relação conjugal é escancarada: Seixas estava no mercado e foi comprado por Aurélia, que não mediria esforços patrimoniais para figurar como ente dominante da relação.

O narrador relata os pensamentos e sentimentos das personagens, a exemplo de Fernando Seixas: "O casamento, desde que não lhe trouxesse posição brilhante e riqueza, era para ele nada menos que um desastre" (Alencar, 1999, p. 111). Assim, também para o sujeito masculino o casamento era uma necessidade premente, constituía uma obrigação social da época.

Noutro trecho da obra, o divórcio, instituto imbricado ao casamento, é apresentado sob viés que reforça a condição - ainda que revertida, ao final da obra - de sujeito da mulher. Embora desde a noite de núpcias Aurélia o tenha mencionado, ressaltando que haveria um receio do escândalo que o divórcio causaria, a posição que a protagonista assume, de a todo tempo reafirmar sua condição de sujeito do matrimônio, encontrando um marido que, simultaneamente, avoca a obrigação de obedecer como servo e cumprir o papel social de marido, torna a relação entre ambos bastante tensa em diversos momentos. Vejamos como o narrador (Alencar, 1999, p. 175-176) trata da temática, num diálogo do casal:

- Nossos destinos estão ligados para sempre. A sorte recusou-me a felicidade que sonhei. Tive este capricho que nenhuma outra o possuiria, enquanto eu viva. Mas não pretendo condená-lo ao suplício desta existência, que vivemos há mais de um mês. Não o retenho; é livre; disponha de seu tempo como lhe aprouver; não tem que dar-me contas.

A moça calou-se esperando uma resposta.

- A senhora deseja ficar só? perguntou Seixas. Ordene, que eu me retiro, agora como em qualquer outra ocasião.

- Não me compreendeu. Há um meio de aliviar-lhe o peso dessa cadeia que nos prende fatalmente e de poupar-lhe 
as constantes explosões de meu gênio excêntrico. É o divórcio que lhe ofereço.

- O divórcio? exclamou Seixas com vivacidade.

- Pode tratar dele quando quiser, respondeu Aurélia com um tom firme e afastou-se.

A partir de então, Seixas intensifica a busca pela sua "alforria", enquanto o ideário romântico torna o envolvimento sentimental das personagens cada vez mais intenso. Quando finalmente consegue juntar renda suficiente para cobrir o dote, é que o discurso jurídico patriarcalista de Alencar se desvela. Seixas anula o domínio da protagonista sobre ele e assume a condição de sujeito principal da sociedade conjugal. Segundo Tapioca Neto (2016, online): “[...] Alencar devolvia suas personagens aos papeis preestabelecidos pela ordem patriarcal oitocentista. Aurélia, antes a Senhora, recusou a posição de elemento dominante do casamento para finalmente se subjetivar na condição de elemento dominado [...]", fenômeno esse que se apresenta, por exemplo, nos seguintes excertos da obra de Alencar (1999, p. 242):

- Pois bem, agora ajoelho-me eu a teus pés, Fernando, e suplico-te que aceites meu amor, este amor que nunca deixou de ser teu, ainda quando mais cruelmente ofendia-te.

$[\ldots]$

- Aquela que te humilhou, aqui a tens abatida, no mesmo lugar onde ultrajou-te, nas iras de sua paixão. Aqui a tens implorando seu perdão e feliz porque te adora, como senhor de sua alma.

Entendemos, nesse ponto, remetermos aos afluxos teóricos de Foucault (2015), para o qual o sujeito sofre o assujeitamento, através do fenômeno ideológico. $\mathrm{Na}$ análise de Orlandi (2006), a ideologia assujeita o indivíduo, e o faz interpelando-o através do discurso. Na narrativa do casamento em Senhora, a ideologia jurídica dominante, patriarcalista, da qual José de Alencar figura como expoente - tanto no direito quanto na literatura - acaba por assujeitar Aurélia Camargo, que, movida por vingança, renuncia sua condição de empoderamento em curso, frustrandoo, e relega-se à condição própria da mulher do Brasil burguês do século XIX, conquanto ente dominado pelo cônjuge. 


\section{AURÉliA CAMARGO: SUJEITO FEMININO DE DIREITO E DE LINGUAGEM}

Após abordarmos as narrativas da herança e do casamento, incumbenos perquirir o que o discurso alencariano nos desvela de Aurélia Camargo a fim de verificara hipótese inicial deste trabalho, a de que o romance Senhora revela um discurso jurídico de ordem patriarcalista e patrimonialista e, nesse viés, constrói a narrativa de aparente empoderamento feminino pela aquisição do patrimônio e consequente constituição como sujeito feminino de direito no bojo de intrincadas relações de assujeitamento. Reitere-se a pertinência da investigação, haja vista a análise dos discursos jurídicos presentes na literatura servirem à compreensão do direito e da sociedade, haja vista o imbricamento entre direito e literatura. Afinal, como bem observado por Hans-Georg Gadamer (2015), a obra de arte é um jogo que só se completa quando acolhida pelo espectador.

A compreensão do discurso jurídico no universo romanesco nos permite saber mais sobre institutos jurídicos e padrões de gênero pretéritos na sociedade. Aliemos a esse entendimento a compreensão de que a identidade feminina é um construto histórico-cultural, cujo processo nos é apresentado por Beauvoir (2009, p. 79):

O mundo sempre pertenceu aos machos. Nenhuma das razões que nos propuseram para explicá-lo nos pareceu suficiente. É revendo à luz da filosofia existencial os dados da pré-história e da etnografia que poderemos compreender como a hierarquia dos sexos se estabeleceu. Já verificamos que, quando duas categorias humanas se acham presentes, cada uma delas quer impor à outra sua soberania; quando ambas estão em estado de sustentar a reivindicação, cria-se entre elas, seja na hostilidade, seja na amizade, sempre na tensão, uma relação de reciprocidade. Se uma das duas é privilegiada, ela domina a outra e tudo faz para mantê-la na opressão. Compreende-se pois que o homem tenha tido vontade de dominar a mulher.

Além da escravização da mulher à função geradora, que limita a sua participação na construção do mundo, pois voltada ao trabalho doméstico, o privilégio econômico dos homens, o valor social que ocupam, o prestígio do casamento, a utilidade que o apoio masculino representa, tudo acaba por impelir às mulheres ao desejo ardoroso de agradar os homens. Permanece, tal qual o servo para a sociedade feudal, a situação de vassala da mulher. Como consequência, aponta a filósofa (2009, p. 155): 
[...] A mulher se conhece e se escolhe, não tal como existe para si, mas tal qual o homem a define. Cumpre-nos, portanto, descrevê-la primeiramente como os homens a sonham, desde que seu ser-para-os-homens é um dos elementos essenciais de sua condição concreta.

Em Senhora, percebemos como a construção de identidade da personagem Aurélia é moldada por homens: da órfã pobre a expor-se na janela em razão do não reconhecimento do avô, da personalidade de moça romântica e sonhadora à Senhora vingativa e, depois, suplicante vulnerável do amor de Fernando Seixas.

No processo de composição da identidade feminina, Hannah Arendt (2007) ressalta que incumbe ao homem a tarefa de manutenção do indivíduo e, por conseguinte, a sobrevivência da mulher. Com isso, há um ideário de superioridade masculina e inferioridade feminina, relegando a mulher à condição de subalterna, de não ter se constituído historicamente como sujeito. Tereza Cristina Pereira Carvalho Fagundes (2003) ressalta que também sob a perspectiva da teoria do direito se constrói a argumentação patriarcal para estabelecimento e manutenção do poder. A identidade feminina é diminuída e se inscreve nas relações de exploração e na razão das pessoas, perenizando o movimento na dominação simbólica, apontada por Bourdieu (2014).

Para verificarmos se Aurélia Camargo- personagem feminina e, portanto, inserta no espectro da dominação simbólica - seria passível de figurar como sujeito de direito e sujeito de linguagem, devemos explicitar quais os sentidos dessas categorias. Tradicionalmente, o sujeito de direito aparece como ser dotado de razão, senhor de seu agir. Segundo Kelsen (2006, p. 191), "a teoria tradicional identifica o conceito de sujeito jurídico com o de pessoa. Eis sua definição: pessoa é o homem enquanto sujeito de direitos e deveres" (grifo nosso). O sujeito de direito, racional e universal, vincula-se à compreensão de indivíduo apto a raciocinar, agir livremente e dominar os objetos do mundo, tornando-se submetido a uma ordem jurídica. Para Miguel Reale (2002), é a ele (e devemos frisar a preponderância, na língua, do emprego do gênero masculino como o generalizante) que incumbe o dever de cumprimento ou o poder de exigir, ou ainda, ambos.

À luz da Teoria Imaginária do Direito, entendemos que o fenômeno jurídico se desvela como modo pelo qual a sociedade conhece o 
comportamento esperado de cada um de seus membros. O discurso jurídico presente em Senhora permite verificar o comportamento esperado da mulher do século XIX. Aurélia encarna a representação do feminino e da racionalidade romantizada - o romance se insere no Romantismo. É interessante observar as limitações impostas pelo Direito ao exercício pleno e autônomo da razão ao sujeito feminino representado pela personagem. No romance, isso fica evidenciado quando é necessário que Aurélia se utilize do aporte da figura do seu tutor, o Sr. Lemos, para a realização de diversos atos jurídicos. Conquanto representação do sujeito feminino de direito, Aurélia denota conhecimento dos direitos a que faz jus, ainda que limitados às suas condições de mulher, órfã e tutelada. É o que extraímos, por exemplo, do diálogo que trava com o seu tutor:

- Perdão, meu tio, não entendo sua linguagem figurada. Digo-lhe que escolhi o homem com quem me hei de casar.

- Já compreendo. Mas bem vê!... Como tutor, tenho de dar a minha aprovação.

- Decerto, meu tutor; mas essa aprovação o senhor não há de ser tão cruel que a negue. Se o fizer, o que eu não espero, o juiz de órfãos a suprirá.

- O juiz?... Que histórias são essas que lhe andam metendo na cabeça, Aurélia?

- Sr. Lemos, disse a moça pausadamente e traspassando com um olhar frio a vista perplexa do velho; completei dezenove anos; posso requerer um suplemento de idade mostrando que tenho capacidade para reger minha pessoa e bens; com maioria de razão obterei do juiz de órfãos apesar de sua oposição, um alvará de licença para casar-me com quem eu quiser. Se estes argumentos jurídicos não lhe satisfazem, apresentar-lhe-ei um que me é pessoal (ALENCAR, 1999, p. 29).

Considerando que José de Alencar traz para o enredo o seu conhecimento jurídico e a personagem Aurélia era menor de 21 anos, é interessante observar as determinações legais a que estaria sujeita, à época. As Ordenações Filipinas (Livro I, Título LXXXVIII, $§ \S 19$ e 27) determinariam a Aurélia a necessidade de um adulto legalmente constituído, como seu responsável, para lhe dar permissão para casar (exigência feita o também aos homens, já que o texto legal se referia aos “órfãos”). Com o falecimento de seus pais, tal permissão poderia ser dada por seu tutor, atribuído pelo Judiciário. Caso seu tutor apresentasse oposição, Aurélia, poderia, ainda, requerer o suplemento de idade (autorizado desde os 18 anos), - similar ao suprimento da atual 
emancipação -, previsto no Livro I, Título LXXXVIII, §§ 27 e 28, instrumento pelo qual poderia confirmar sua capacidade de reger a vida independentemente. Neste caso, seria necessário produzir prova testemunhal e a demanda ainda passaria pelo crivo do Curador Geral dos Órfãos, que intercedia nos feitos que envolviam interesses de menores e incapazes, conforme previsão do Livro III, Títulos XLI e LXXV das Ordenações Filipinas. Era, ainda que complexo, possível, e é isso que a fala da protagonista exterioriza: ela tinha ciência de institutos jurídicos e de mecanismos processuais, adquirindo uma visão de sujeito racionalista.

\footnotetext{
- Isto quer dizer que se eu tivesse um tutor que me contrariasse e caísse em meu desagrado, ao chegar à minha maioridade não lhe daria quitação, sem primeiro passar um exame nas contas de sua administração para o que felizmente não careço de advogado nem de guardalivros.

$[\ldots]$

- Neste caso, em vez de matar a paciência e aborrecer-me com autos e contas, dou tudo por bem-feito. Ainda mais, sei que a tutela é gratuita, mas assim não deve ser quando os órfãos têm de sobra com que recompensar o trabalho que dão. (ALENCAR, 1999, p. 30).
}

Quando se casasse, entretanto, tal independência seria reduzida: deveria reverência marital (visto que conforme o Livro IV, Título XCV das Ordenações Filipinas, o marido era o chefe do casal) e poderia até ser castigada corporalmente, tal qual o filho e o escravo (Livro V, Título XXXVI, das Ordenações Filipinas). É interessante perceber que à luz da lei da época, uma órfã que se livrou da tutela é mais autônoma do que uma mulher casada.

Para Bakhtin (2009), a constituição do sujeito se dá na interação com o outro, quando o sujeito se completa. Esse sujeito, interpelado pela ideologia como tal, permanece numa articulação dialógica, constituído pelo outro e constituinte do outro. Para Bakhtin, os sujeitos habitam e são habitados por diferentes vozes. A interação verbal é o espaço de constituição da linguagem, permitindo que, ao dialogarmos uns com os outros, participemos do processo de constituição de sujeitos. O outro do sujeito é um "nós".

$\mathrm{Na}$ representação de Aurélia, a construção identitária enquanto sujeito é possível apenas quando ela se relaciona com Seixas: o enredo ganha corpo ao utilizar a herança adquirida pela via testamentária para 
alcançar o outro, e, depois de adquiri-lo, torna-se completo, quando relega ao outro a condução do seu futuro enquanto esposa subalterna. Não obstante, a senhora rica, que poderia ter seguido o caminho do suplemento de idade, tornando-se apta a reger sua vida autonomamente, escolheu, num comportamento esperado pelos membros da sociedade (como é próprio do fenômeno jurídico, à luz da Teoria Imaginária), o caminho do casamento.

A Senhora se assujeita na relação com o outro, objeto do seu desejo. Para Foucault (2006), o sujeito é formado em sua sujeição, o que permite construir sua identidade, já que é a submissão a condição primeira de possibilidade de existência. Mesmo a submissão transitória de Fernando Seixas a Aurélia serve para "criar a ideia da mulher como um ser cuja plenitude residiria em sua relação com um homem, construindo-se uma identidade nele centrada” como bem observa Ana Carolina Eiras Coelho Soares (2010). Foucault (1985) demonstra que o sexo é componente determinante e fundamental da identidade. Lembremos, com Culler (1999), que a ideia de sexo também é construída na literatura. Abrir mão da autonomia para se constituir enquanto mulher casada, como faz Aurélia, significa construir uma identidade que se define na relação com o outro consoante os papéis de gênero impostos pela ideologia. Ideologia que, consoante Althusser (1980), representa a relação imaginária de indivíduos com suas reais condições de existência, interpelando indivíduos em sujeitos, ao se assujeitarem em práticas reguladas por aparelhos ideológicos.

Ilustra-se esse movimento em Senhora, na relação matrimonial de Aurélia e Seixas, mas também ao assumir características "masculinas" para sustentar a família. Diz-nos o narrador (Alencar, 1999, p. 91), denotando superioridade masculina: "A natureza dotara Aurélia com a inteligência viva e brilhante da mulher de talento, que se não atinge ao vigoroso raciocínio de homem, tem a preciosa ductilidade de prestar-se a todos os assuntos, por mais diversos que sejam”. Culler (1999) ressalta que a literatura provoca a identificação do leitor com as personagens e auxilia na formação de sua identidade - numa interpretação conjunta desse entendimento com aquele que nos é trazido por Bakhtin (2009), podemos inferir que as obras literárias desvelam interações entre leitor e escritor por meio de representações de mundo compartilhadas, o que produz, na construção da identidade do leitor, ecos das vozes das figuras fictícias. A identificação da personagem com o 
leitor é buscada por Alencar (1999, p. 92-3) no uso da generalização: "Como todas as mulheres de imaginação e sentimento, ela achava dentro em si, nas cismas do pensamento, essa aurora d'alma que se chama o ideal, e que doura ao longe com sua doce luz os horizontes da vida".

Importante mencionar a questão do mito da busca, apresentada por Ellen H. Douglas (1990). A tradição patriarcal traz as noções do herói que conquista seus objetivos e da heroína passiva. A mulher, o outro do herói, construirá sua identidade a partir do masculino que irá encontrá-la. Segundo Ana Carolina Eiras Coelho Soares (2010), em Senhora, esse mito se dá de modo reverso. No entanto, a busca não é feminista, mas meramente feminina, pois, embora realizada por uma mulher, mantém-se a estrutura patriarcalista.

À luz dos marcos teóricos apontados, percebemos que a narrativa ficcional elaborada em Senhora expõe expectativas de comportamento dos membros da sociedade oitocentista, por meio da literatura. Com isso, desvela um discurso jurídico em que poder e direito se articulam e constitui a protagonista como sujeito de linguagem e feminino de direito, ao assujeitá-la nas relações de poder com o outro, atravessadas pela ideologia, fenômeno que perpassa a figura do tutor, da condição do sexo feminino, do empoderamento em curso, conquistado através do patrimônio, e a frustração desse empoderamento em função do sexo oposto (vingança amorosa) e sua renúncia como súplica pelo amor.

\section{CONSIDERAÇÕES FINAIS}

A aproximação entre direito e literatura é possível porque ambas as áreas desvelam discursos ficcionais. Assim como a literatura, o direito possui caráter imaginário, além de representar o modo pelo qual a sociedade conhece o comportamento dos seus membros. Em ambas, a dimensão ficcional do discurso representa possibilidades reduzidas, cuja realidade só permite saber o que nos informam os autores das obras. Com isso, ocultam aquilo que seus criadores desejam que seja ocultado - o próprio funcionamento da ideologia jurídica.

Nessa perspectiva, o presente trabalho se inseriu no viés do "direito na literatura”, por examinar aspectos da problemática e experiência jurídica retratados em Senhora, percebendo a virtualidade da obra como catalisador 
da compreensão do fenômeno jurídico e de seus discursos, institutos e procedimentos, encontrando desvelamentos do discurso jurídico que refletiram papéis de gênero nos institutos vigentes à época em que viveu José de Alencar.

Sendo a Literatura o lócus do trabalho lúdico com a linguagem, e esta, entendida como formal e atravessada por entradas subjetivas e sociais, percebemos em Senhora a articulação de processos ideológicos do autor. Com suporte em Foucault e Guerra Filho, vimos que a obra literária veicula discursos, articulando saberes e poderes. O direito camuflou o poder patriarcal, encenando a narrativa da verdade ficcionalizada de Aurélia. Em Senhora, esse fenômeno se desvelou na narrativa da herança, que apresenta distinções jurídico-ficcionais entre filhos, e na sucessão testamentária, também camuflada, que surpreende a herdeira universal. Percebemos, com isso, as engrenagens do fenômeno jurídico, que perpetuam a ideologia da classe dominante e legitimam seus privilégios e poderes.

Interessante o imbricar entre as temáticas sucessória, matrimonial e constituição e realização do sujeito e perfil feminino do enredo. A partir dos direitos sucessórios, a negociação perpassa o casamento de Aurélia e Seixas e flui para a ascensão social da mulher e seu assujeitamento ao se constituir em mulher casada. Desse modo, Senhora é um frutífero exemplo de como, por meio da literatura, o direito se revela como instrumento de conhecimento do comportamento esperado de cada um de seus membros, tal como preconizado pela Teoria Imaginária do Direito, a partir da qual podemos afirmar que a ênfase no caráter patrimonial do casamento nos permite concluir ser essa a perspectiva do casamento arranjado, da "amostra de balcão" e da estrutura jurídico-social em torno desse instituto. Assim, percebemos em Senhora a vivência da construção sócio-jurídica patriarcal, estando o homem no centro da identidade da relação marital (não por acaso a palavra deriva de marido) e, ainda mais, na construção da identidade assujeitada feminina, já que é ao frustrar seu empoderamento e suplicar pelo amor e submissão ao seu cônjuge que Aurélia Camargo verdadeiramente completa o ideário romântico preconizado por Alencar.

Embora, à primeira vista, a personalidade altiva, a riqueza e o modo com que reivindica a todo tempo a condição de sujeito da história - seja na relação matrimonial com Seixas, seja na condição de pupila, capaz de gerir 
a tutela - nos façam crer que há uma condição de empoderamento e reconhecimento da condição de sujeito da mulher, em verdade, Alencar o faz apenas sob a perspectiva de criá-la como um ser-para-o-homem. A identidade, pois, está nele centrada, mantendo o viés patriarcalista, ainda que sob um enfoque feminino: o homem, "traste indispensável”, é condição necessária à constituição do sujeito feminino, que ocorre pelo assujeitamento ao homem e à ideologia patriarcal - Aurélia é formada em sua sujeição, através das relações de poder, inicia o curso de seu empoderamento ao adquirir patrimônio por via sucessória e, submetendose ao controle e dependência da relação matrimonial patriarcal, assujeitase, frustrando seu empoderamento. Não é demais ressaltar que Aurélia, enquanto personagem ficcional, representa o imaginário de toda a sociedade, diante da voz polifônica do sujeito.

A submissão enquanto condição de existência, em termos foucaultianos, é vivenciada por Aurélia Camargo: a protagonista cumpre seu papel apenas quando anula sua condição de sujeito da história, revelando-se, como indica o subtítulo do romance, um "perfil de mulher", insculpindo-a com institutos jurídicos e procedimentos capazes de revelar o direito e o aparato social da época, diante da voz polifônica bakhtiniana do sujeito que enuncia o discurso, inclusive ao escrever a obra literária. Com isso, desvela-se, sob a ótica da Teoria Imaginária, o comportamento esperado dos membros da sociedade: Aurélia revela um "perfil". Alencar nos mostra um retrato da mulher burguesa brasileira dos Oitocentos, e o discurso jurídico literário por ele construído nos desvela o que a sociedade oitocentista esperava dela.

\section{REFERÊNCIAS}

ALENCAR, José de. Senhora: perfil de mulher. 6. ed. São Paulo: FTD, 1999 (Coleção Grandes Leituras).

ALMEIDA, Cândido Mendes de. Codigo Philippino, ou, Ordenações e leis do Reino de Portugal: recopiladas por mandado d'El-Rey D. Philippe I. Rio de Janeiro: Typ. do Instituto Philomathico, 1870. Disponível em: http://www2.senado.leg.br/bdsf/item/id/242733 http://www1.ci.uc.pt/ihti/proj/filipinas/. Acesso em: 18 out. 2016.

ALTHUSSER, Louis. Ideologia e aparelhos ideológicos de Estado. 3. ed. Lisboa: Presença, 1980. 
ARENDT, Hannah. A condição humana. 10. ed. Rio de Janeiro: Forense Universitária, 2007.

BAKHTIN, Mikhail. Marxismo e filosofia da linguagem. Trad. de Michel Lahud e Yara Frateschi Vieira. 13. ed. São Paulo: Hucitec, 2009.

BATLIWALA, Srilatha. El significado del empoderamiento de las mujeres: nuevos conceptos desde la acción. In: LEÓN, Magdalena. Poder y empoderamiento das mujeres. Bogotá: TM Editores, 1997.

BEAUVOIR, Simone de. O segundo sexo. Trad. de Sérgio Milliet. 2. ed. Rio de Janeiro: Nova Fronteira, 2009.

BRANDÃO, Helena H. Nagamine. Introdução à análise do discurso. 2. ed. rev. Campinas: Unicamp, 2004.

BOURDIEU, Pierre. A dominação masculina. Trad. de Maria Helena Kühner. Rio de Janeiro: Bertrand Brasil, 2014.

CANDIDO, Antonio. Literatura e sociedade. 9. ed. rev. Rio de Janeiro: Ouro sobre Azul, 2006.

CULLER, Jonathan. Teoria literária: uma introdução. Trad. de Sandra Vasconcelos. São Paulo: Beca Produções Culturais, 1999.

D’INCAO, Maria Ângela. Mulher e família burguesa. In: DEL PRIORE, Mary (Org.). História das mulheres no Brasil. Org. de Carla Bassanezi. 5. ed. São Paulo: Contexto, 2001.

DOUGLAS, Ellen H. A busca feminista em Perto do coração selvagem. In: GOTLIB, Nádia Batella (Org.). A mulher na literatura. Vol. II. Belo Horizonte: UFMG, 1990. p.71-79.

EDELMAN, Bernard. O direito captado pela fotografia: elementos para uma teoria marxista do direito. Coimbra: Centelha, 1976.

FAGUNDES, Tereza Cristina Pereira Carvalho. Identidade feminina: uma construção histórico-cultural. In: FAGUNDES, Tereza Cristina Pereira Carvalho (Org.). Ensaios sobre identidade e gênero. Salvador: Helvécia, 2003.

FOUCAULT, Michel. A ética do cuidado de si como prática da liberdade. In: MOTTA, Manoel B. da (Org.). Ética, sexualidade e política. Trad. de Elisa Monteiro, Inês A. Dourado Barbosa. 2. ed. Rio de Janeiro: Forense Universitária, 2006.

FOUCAULT, Michel. A ordem do discurso. 24. ed. São Paulo: Loyola, 2015 (Coleção Leituras Filosóficas).

FOUCAULT, Michel. Arqueologia do saber. Trad. de L. F. Baeta Neves. Petrópolis: Vozes, 1971.

FOUCAULT, Michel. História da sexualidade I: a vontade de saber. 7. ed. Trad. de Maria Thereza da Costa Albuquerque e J. A. Guilhon Albuquerque. Rio de Janeiro: Graal, 1985. 
GADAMER, Hans-Georg. Verdade e método I: traços fundamentais de uma hermenêutica filosófica. Trad. de Flávio Paulo Meurer. Revisão da tradução por Enio Paulo Giachini. 15. ed. Petrópolis: Vozes; Bragança Paulista: Universitária São Francisco, 2015.

GOLIN, Cida. Mulheres de escritores: subsídios para uma história privada da literatura. São Paulo: Annablume; Caxias do Sul: Educs, 2002.

GRIMM, Jacob. Von der Poesie im Rechte. Zeitschrift für geschichtliche Rechtswissenschaft, Berlim, Ferdinand Dümmler, v. 6, p. 152-191, 1882. Hamburgo, GernotFligge. Disponível em: https://www.hsaugsburg.de/ harsch/germanica/Chronologie/19Jh/GrimmJacob/grj_pro o.html. Acesso em: 01 nov. 2016.

GUERRA FILHO, Willis Santiago. Por uma Poética do Direito: introdução a uma teoria imaginária do Direito (e da totalidade). Panóptica, [s.l.], n. 19, ano 3, p. 19-68, jul./out. 2010.

GUERRA FILHO, Willis Santiago; CANTARINI, Paola. Teoria poética do direito. Rio de Janeiro: Lumen Juris, 2015.

HEIDEGGER, Martin. Ser e tempo. Trad. de Márcia Sá Cavalcante Schuback. 14. ed. Petrópolis: Vozes, 2005.

KANT, Immanuel. A metafísica dos costumes. Trad. de Edson Bini. Bauru: EDIPRO, 2003 (Série Clássicos Edipro).

KELSEN, Hans. Teoria pura do direito. São Paulo: Martins Fontes, 2006.

ORLANDI, Eni Pulcinelli. Discurso e leitura. 7. ed. São Paulo: Cortez, 2006.

REALE, Miguel. Filosofia do direito. 19. ed. São Paulo: Saraiva, 2002.

SOARES, Ana Carolina Eiras Coelho. Nos caminhos da pena de um romancista do século XIX: o Rio de Janeiro de Diva, Lucíola e Senhora. Revista Brasileira de História. São Paulo, v. 30, n. 60, p. 195-209, 2010.

STRECK, Lênio Luiz. O direito e suas ficções. In: STRECK, Lênio Luiz; TRINDADE, André Karam (Org.). Direito e literatura: da realidade da ficção à ficção da realidade. São Paulo: Atlas, 2013.

TAPIOCA NETO, Renato Drummond. A sociedade de corte $e$ a representação da mulher no romance "Senhora" (1875). Comunicação apresentada no VIII Seminário de Pesquisa em História da Universidade Estadual de Santa Cruz. 2014. Disponível em: https://rainhastragicas.com/2014/01/24/a-sociedade-de-corte-e-arepresentacao-da-mulher-no-romance-senhora-1875/. Acesso em: 10 nov. 2016.

TAPIOCA NETO, Renato Drummond. Esposa autônoma, marido submisso: Aurélia Camargo, 'Senhora' de Fernando Seixas. 2016. Disponível em: http://rainhastragicas.com/2016/11/04/esposa-autonomamarido-submisso-aurelia-camargo-senhora-de-fernando-seixas/. Acesso em: 07 nov. 2016.

TRINDADE, André Karam. Kafka e os paradoxos do Direito: da ficção à realidade. Revista Diálogos do Direito, Cachoeirinha, Rio Grande do Sul, v. 2, n. 2, p. 137-159, nov. 2012. 
VIEIRA, Flávia David; SILVA, Edvania Gomes da. O instituto do matrimônio nas Ordenações Filipinas: os efeitos de sentido de "casamento" na legislação portuguesa aplicada no Brasil. Linguasagem, São Carlos, v. 23, n. 1, 2015.

Idioma original: Português Recebido: 16/o6/17

Aceito: 02/11/17 